\title{
A interdisciplinaridade em sala de aula: processamentos cognitivos em atividades de interpretação textual
}

\author{
Interdisciplinariedad en el aula: \\ procesamiento cognitivo en actividades de interpretación \\ textual
}

\section{Interdisciplinarity in the classroom: cognitive processing in textual interpretation activities}

\author{
Emília Cristina Ribeiro dos Santos ${ }^{1}$ \\ Dennys Dikson²
}

\begin{abstract}
RESUMO: O presente artigo traz uma pesquisa realizada no âmbito do Mestrado Profissional em Letras (PROFLETRAS-UFRPE/UAG) sobre leitura, escrita e interpretação de textos escritos numa perspectiva interdisciplinar, com análises dos processamentos cognitivos textuais construídos pelos alunos. Embasamo-nos em estudos sobre gêneros, leitura e processamento textual para destacar o desempenho linguístico de duas alunas do $6^{\circ}$ ano do ensino fundamental de uma escola pública em atividades de leitura-escrita-interpretação, produzidas durante a aplicação de um projeto de intervenção didático-pedagógico interdisciplinar (uma pesquisa-ação) envolvendo Língua Portuguesa, Matemática e Ciências. Com atividades desenvolvidas individualmente para cada disciplina sempre a partir de um mesmo texto, observamos, nas análises, que, para construir as respostas solicitadas em cada questão interpretativa, as crianças, de uma forma ou de outra, vão mobilizando e ativando os processamentos cognitivos a partir de três grandes sistemas de conhecimentos - 0 linguístico, o enciclopédico e interacional $(\mathrm{KOCH}, 2015,2016 ; \mathrm{KOCH}$; ELIAS, 2014). Os
\end{abstract}

\footnotetext{
1 Mestre em Letras pelo Programa de Pós-Graduação em Mestrado Profissional em Letras (PROFLETRAS) da Universidade Federal Rural de Pernambuco, Unidade Acadêmica de Garanhuns (UFRPE/UAG). Professora das redes municipais de ensino das cidades de Petrolina/PE e Juazeiro/BA.

${ }^{2}$ Doutor em Letras e Linguística (UFAL). Professor adjunto do curso de Letras e professor permanente do Programa de Pós-Graduação em Mestrado Profissional em Letras (PROFLETRAS), da Universidade Federal Rural de Pernambuco, Unidade Acadêmica de Garanhuns (UFRPE/UAG).
} 
resultados demonstram quais estratégias cognitivas são mais ou menos ativadas pelas crianças na execução das atividades escolares, situação que permite ao professor traçar estratégias mais específicas para melhorar o processamento cognitivo, a depender de quais conhecimentos e/ou estratégias textuais necessitam ser ativados durante a leitura, interpretação e escrita.

PALAVRAS-CHAVE: Processamento textual. Leitura-escrita-interpretação. Sala de aula. Ação interdisciplinar.

RESUMEN: Este artículo presenta una investigación realizada bajo el Mestrado Profissional em Letras (PROFLETRAS-UFRPE / UAG) sobre lectura, escritura e interpretación de textos escritos en una perspectiva interdisciplinaria, con análisis del procesamiento cognitivo textual construido por los estudiantes. Nos basamos en estudios sobre géneros, lectura y procesamiento de textos para resaltar el desempeño lingüístico de dos estudiantes del sexto grado de una escuela pública en actividades de lectura, escritura e interpretación, producidos durante la aplicación de un proyecto de intervención didáctico-pedagógica interdisciplinaria (una investigación de acción) que involucra la lengua portuguesa, las matemáticas y la ciencia. Con actividades desarrolladas individualmente para cada sujeto siempre a partir del mismo texto, observamos en los análisis que, para construir las respuestas solicitadas en cada pregunta interpretativa, los niños, de una forma u otra, movilizan y activan el procesamiento cognitivo para de tres sistemas de conocimiento principales: el lingüístico, el enciclopédico y el interaccional (KOCH; ELIAS, 2014; KOCH, 2015, 2016). Los resultados muestran qué estrategias cognitivas son más o menos activadas por los niños en el desempeño de las actividades escolares, una situación que le permite al maestro dibujar estrategias más específicas para mejorar el procesamiento cognitivo, dependiendo de qué conocimiento y / o estrategias textuales deben activarse durante la lectura, interpretación y escritura.

PALABRAS-CLAVE: Procesamiento textual. Lectura-escritura-interpretación. Aula acción interdisciplinaria.

ABSTRACT: This article presents a research carried out within the scope of the Professional Master's Degree in Languages (PROFLETRAS-UFRPE/UAG) on reading, writing and interpretation of written texts in an interdisciplinary perspective, analyzing the textual cognitive processes built by the students. We are based in studies on genres, reading and textual processing to highlight the linguistic performance of two 6th grade students in a public school on reading-writing-interpretation activities, produced during the application of a didactic interdisciplinary pedagogy (an action research) involving Portuguese Language, Mathematics and Sciences. With activities developed individually for each discipline, always from the same text, we observe that, in order to construct the requested answers in each interpretative question, the children, in one way or another, are mobilizing and activating the cognitive from three great systems of knowledge - the linguistic, the encyclopedic and interactive $(\mathrm{KOCH}$, ELIAS, 2014, $\mathrm{KOCH}, 2015,2016)$. The results demonstrate which cognitive strategies are more or less activated by children in the execution of school activities, a situation that allows the teacher to devise more specific strategies to improve cognitive processing, depending on what knowledge and/or textual strategies need to be activated during reading, interpretation and writing. 
KEYWORDS: Textual processing. Reading-writing-interpretation. Classroom. Interdisciplinary action.

\section{Introdução}

Sabemos que leitura e escrita em sala de aula são temas que, em especial nas últimas duas décadas, vêm ganhando um espaço primordial nas abordagens das ciências da linguagem, seja no mundo científico-acadêmico, seja na própria graduação, em pós-graduações ou em pesquisas teóricometodológicas e de análises. Isso porque ler, escrever e interpretar não são mais movimentos puramente escolares e de sala de aula, mas assumiram papel de múltiplas interações sociais, de posicionamentos políticos, de formação cultural, de reflexões críticas.

Levando essas premissas em consideração, bem como os resultados recentes de avaliações em larga escala do Ensino Fundamental e Médio no país e, sobretudo, o lugar que ocupa a leitura no exercício da cidadania, percebemos a necessidade de continuar trazendo para o foco de atenção estudos e pesquisas que abarquem tal assunto, pois não podemos fechar os olhos para um dos grandes problemas - dificuldades em leitura/escrita - que ainda afetam as escolas brasileiras.

Tendo como ponto central essa alta relevância sócio-histórica que leitura-escrita carrega, em especial, no nosso caso, em ambiente pedagógico, o presente artigo traz um recorte de uma investigação - desenvolvida no âmbito do PROFLETRAS da UFRPE/UAG ${ }^{3}$ - que realizou uma intervenção didáticopedagógica aplicada em uma escola pública, de forma interdisciplinar com as disciplinas Língua Portuguesa, Matemática e Ciências, para melhoria das competências linguísticas de leitura, escrita e interpretação dos alunos, tendo como foco principal a análise de estratégias do processamento textual ativadas quando das respectivas interpretações materializadas na escrita dos alunos, a

\footnotetext{
3 Programa de Pós-Graduação em Mestrado Profissional em Letras (PROFLETRAS), da Universidade Federal Rural de Pernambuco, Unidade Acadêmica de Garanhuns (UFRPE/UAG). Entretextos, Londrina, v. 19, n. 2, p. 108- 140 / 2019 
partir de um mesmo texto trabalhado diferentemente em cada uma das mencionadas disciplinas.

Para tanto, como base teórico-metodológica, apoiamo-nos em pontos relevantes sobre gêneros textuais-discursivos, em especial voltados para o ensino, com concepções tecidas por Bakhtin (1992), Marcuschi (2008), Bazerman (2007); sobre a relevância da leitura no ambiente escolar, através de Antunes (2003, 2009), Koch e Elias (2014), Koch e Cunha-Lima (2005), entre outros; acerca da leitura na perspectiva interdisciplinar, à luz dos estudos de Fazenda (2008) e Japiassu (1972); e, quanto ao processamento textual, com Koch e Elias (2014) e Koch $(2015,2016)$, que defendem uma leitura a partir da mobilização dos conhecimentos cognitivos armazenados na memória por meio do processamento textual.

Ao abordarmos a leitura e a escrita-interpretação na perspectiva interdisciplinar, o nosso trabalho assume relevância em relação a outros que tratam do mesmo tema, considerando que integramos três grandes áreas do conhecimento, através das disciplinas insertas do projeto, desmistificando, por um lado, a tentativa de responsabilizar leitura-escrita como sendo exclusiva do professor de Português; e, por outro, que um mesmo texto carregaria inúmeras dificuldades de ser trabalhado em disciplinas diferentes - essas situações prático-pedagógicas, entrelaçando áreas e professores diferentes, nos fizeram imprimir importantes passos para procurar compreender como o processamento textual interpretativo funciona em cada uma das disciplinas, quando as crianças leem, interpretam e escrevem suas respostas nas atividades escolares.

\section{0 gênero enquanto ponto de partida}

Já é consenso entre linguistas e estudiosos do assunto que a interação social só acontece na e pela linguagem, e por ela o sujeito se faz presente nos discursos circundantes da vida e da cultura. Compreender o outro e fazer-se compreender, dizer o que sente, agir e interagir nas múltiplas semioses dos gêneros de linguagem. Os gêneros textuais-discursivos são, portanto, parte Entretextos, Londrina, v. 19, n. 2, p. 108- 140 / 2019 
constituinte das nossas ações na vida, refletindo praticamente todas movimentações construídas sócio-historicamente pelos sujeitos.

Ao nos debruçarmos sobre esse tema de interessante relevância, vale destacar a forte e significativa contribuição do filósofo russo Bakhtin (1992) para os estudos e pesquisas realizados no Brasil. Assim, é praticamente impossível discorrer, pesquisar e argumentar sobre a teoria dos gêneros sem citar Bakhtin como pano de fundo e alicerce indispensável, pois o que observamos é que a maioria das pesquisas, mesmo apontando para uma diversidade terminológica no campo conceitual ou abordando, teoricamente, de forma diferente o mesmo objeto de estudo, parte fundamentalmente das bases teóricas dele. Para o pesquisador, o gênero é o recurso da interação humana, pois

A riqueza e a diversidade dos gêneros do discurso são infinitas porque são inesgotáveis as possibilidades da multiforme atividade humana e porque em cada campo dessa atividade é integral o repertório de gêneros do discurso, que cresce e se diferencia à medida que se desenvolve e se complexifica um determinado campo. Cabe salientar em especial a extrema heterogeneidade dos gêneros do discurso (orais e escritos) [...] (BAKHTIN, 1992, p. 262).

De acordo com Bakhtin (1992, p. 285), toda essa diversidade de gêneros se justifica na pluralidade de discursos, que se manifestam nas atividades humanas. Nesse processo de troca e de interação humana, "os gêneros dos discursos são tão indispensáveis para a compreensão mútua quanto as formas da língua". Nesse paralelo entre gênero e língua, compreendemos que

Quanto melhor dominamos os gêneros tanto mais livremente os empregamos, tanto mais plena e nitidamente descobrimos neles a nossa individualidade (onde isso e possível e necessária), refletimos de modo mais flexível e sutil a situação singular da comunicação; em suma, realizamos de modo mais acabado o nosso livre projeto de discurso. (BAKHTIN, 1992, p. 285).

Nesse sentido, levando a discussão para nossa área, compreendemos que, quando o professor de língua materna cria as condições de acesso e de 
estudo da linguagem por meio dos gêneros, dos mais variados e concretamente possíveis de realização, considerando o seu espaço de produção e de recepção, possibilita aos alunos uma proficiência cada vez mais robusta em seu domínio, ampliando sua competência comunicativa.

Assim, quanto mais o indivíduo desenvolver a sua capacidade de uso da linguagem, melhor estará para interagir, de forma produtiva, crítica e eficiente, nos contextos sociais. Por esse motivo, "vale tomar os gêneros como referência para o estudo da língua e, consequentemente, para o desenvolvimento de competências em fala, em escuta, em leitura e em escrita dos fatos verbais com que interagimos socialmente" (ANTUNES, 2009, p. 57). Essa proposta de ensino a partir dos gêneros deve possibilitar o conhecimento amplo que não reduza o gênero a aspectos estruturais, na medida em que

"[...] não concebamos os gêneros como modelos estanques, nem como estruturas rígidas, mas como formas culturais e cognitivas de ação social corporificadas de modo particular na linguagem, temos de ver os gêneros como entidades dinâmicas". (MARCUSCHI, 2008, p. 156).

Diante disso, compreendemos que os gêneros assumem um papel social e, por isso não podemos concebê-los enquanto modelos totalmente estáveis e rígidos, mas flexíveis e dinâmicos a serviço das interações humanas, desempenhando o papel funcional da linguagem. Esse aspecto cultural e cognitivo dos gêneros nos leva a relacioná-los ao pressuposto da textualidade, que contribui para o processamento cognitivo, considerando que

O conceito de "gêneros textuais", portanto, retoma - ampliando-o, no entanto - um pressuposto básico da textualidade: o de que a língua usada nos textos - dentro de determinado grupo - constitui uma forma de comportamento social. Ou seja, as pessoas cumprem determinadas atuações sociais por meios verbais, e tais atuações - a exemplo de todo o social - são tipificadas, estabilizadas; por outras palavras, são sujeitas a modelos, em que a recorrência de certos elementos Ihes dá exatamente esse caráter de estabelecido, de típico, de regular. É esse caráter de "regular" que faz com que o próprio conteúdo de um gênero possa ser previsto. (ANTUNES, 2009, p. 5455 , grifo da autora) 
Dessa maneira, quanto mais as pessoas atuam nos espaços sociais, melhor fazem uso dos variados repertórios linguísticos para a produção e recepção de gêneros, porque, principalmente, essas atuações sociais estão sujeitas a modelos, ou seja, a certa regularidade. Essas formas de enunciados que se apresentam relativamente estáveis e disponíveis na nossa cultura nos levam a associar determinadas características a certos gêneros, considerando que "os indivíduos desenvolvem uma competência metagenérica que thes possibilita interagir de forma conveniente, na medida em que se envolvem nas diversas práticas sociais" (KOCH; ELIAS, 2014, p. 102). É essa competência que produz nos sujeitos a capacidade de lidar, reconhecer, produzir, adequar e compreender os gêneros a fim de realizar o processo comunicativo, pois "se, por um lado, a competência metagenérica orienta a produção de nossas práticas comunicativas, por outro lado, é essa mesma competência que orienta a nossa compreensão sobre os gêneros textuais efetivamente produzidos" (KOCH; ELIAS, 2014, p. 103).

Dita competência metagenérica capacita os sujeitos a reconhecer, prever e ajustar os gêneros de acordo com sua finalidade, suas intenções e seus objetivos. Quanto mais expostos às atividades de linguagem verbal/escrita nas diversas situações, mais os sujeitos ampliarão o seu repertório de gêneros, desenvolvendo, portanto, a capacidade de produção e interação de acordo com o seu propósito comunicativo nas esferas sociais.

Nessa perspectiva, Bazerman (2007, p. 196) argumenta que "[...] os ambientes pedagógicos nunca deveriam ser despojados da complexidade significante dos ambientes comunicativos fora dos mundos da sala de aula". Por essa razão, a escola precisa reinventar os espaços de aprendizagem a fim de ressignificar os processos de ensinar e de aprender, de ler e de escrever, de forma que tanto professor quanto estudante possam compreender a dinâmica e a complexidade das relações humanas nos contextos sociais de comunicação, tendo, sempre, os gêneros textuais-discursivos como ponto de partida. 


\section{Algumas concepções de leitura}

Por muito tempo, a habilidade de leitura, seja qual for o gênero, foi atribuída à capacidade de decodificar o texto escrito. Bastava alfabetizar a criança e lançá-la aos desafios da leitura do texto, como se já estivesse pronta para ler e compreender as tramas e as pistas do que se apresentava no papel. Isso porque para a grande maioria dos professores, o texto era (e infelizmente, para muitos, ainda é) visto como algo pronto e acabado e ao aluno cabia a tarefa de "catar" informações explícitas no texto, que continha todas as informações necessárias para o leitor compreendê-lo, desde que soubesse decodificá-lo.

Hoje, porém, já se compreende que a leitura é uma atividade complexa, um encontro entre quem lê e o autor, mediado pelo texto e, nesse processo, o leitor constrói sentidos a partir das informações e pistas no texto e de seus conhecimentos de mundo, ativados pelo processamento textual, sendo, portanto, concebida "como atividade interativa altamente complexa de produção de sentidos" (KOCH; ELIAS, 2014, p. 11).

A partir dessa concepção, compreendemos que a leitura não é um ato solitário e que todo o processo gira em torno de um encontro entre leitor-textoautor. Koch e Cunha-Lima (2005) defendem que os sentidos do texto são resultados dos processos mentais mobilizados nessa interação. Considera-se, portanto, o texto como processo e situado num dado contexto; sua compreensão e produção dependem da capacidade dos falantes da língua:

\footnotetext{
Os textos não são explícitos, não trazem na sua superfície tudo o que é preciso saber para compreendê-los. Não trazem tampouco uma instrução explícita de preenchimento das lacunas que permita chegar a uma compreensão inequívoca do seu sentido. Todo o texto requer uma atividade de "enriquecimento" das formas que estão na superfície, do emprego de conhecimentos prévios e de várias estratégias interpretativas. Esse conhecimento é dado como certo por todos os usuários da língua, embora não existam regras claras de

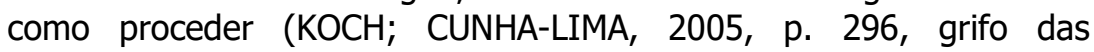
autoras).
} 
Corroborando com esse pressuposto de Koch e Cunha-Lima (2005), Cafiero (2010, p. 86) assevera que "[...] ler é atribuir sentidos. E, ao compreender o texto como um todo coerente, o leitor pode ser capaz de refletir sobre ele, de criticá-lo, de saber como usá-lo em sua vida". Nessa concepção de leitura, o leitor não é aquele ser passivo que apenas decodifica as palavras e localiza informações localizadas nos gêneros textuais. O leitor é, sobretudo, um agente da leitura que interage com o texto e, na busca e construção de significados, num processo de interlocução com o autor, mobiliza seus conhecimentos de mundo, podendo refutar as ideias ou ainda concordar com elas para acrescentá-las no seu universo de saberes. Concordamos com Cafiero (2010, p. 86) quando afirma que "[...] o leitor - um sujeito que atua socialmente, construindo experiências e história - compreende o que está escrito a partir das relações que estabelece entre as informações do texto e seus conhecimentos de mundo".

Dessa forma, tanto Cafiero (2010) quanto Koch e Cunha-Lima (2005) indicam que o texto não é um todo explícito; os sentidos não estão ali prontos e não são perceptíveis pela leitura superficial ou pela simples decodificação, necessitando-se, portanto, levar os estudantes a criarem estratégias de compreensão a fim da construção significativa de sentidos e de posicionamentos críticos a respeito do que é tratado. E isso somente será possível quando o estudante/leitor mobilizar seus conhecimentos previamente construídos e as operações mentais necessárias para entender o processo de proliferação de sentidos do texto.

A esse pressuposto, Antunes (2003, p. 66) acrescenta "[...] a leitura é parte da interação verbal escrita, enquanto implica a participação cooperativa do leitor na interpretação e na reconstrução do sentido e das intenções pretendidos pelo autor". Considerando a leitura esse lugar de interação, concordamos com Geraldi (2012, p. 107) quando afirma:

A leitura, por sua vez, é entendida como um processo de interlocução entre leitor/texto/autor. $\mathrm{O}$ aluno-leitor não é passivo, mas agente que busca significações. E nesse processo de leitura, de interlocução do 
aluno-leitor com o texto/autor, a posição do professor não é a do mediador do processo que dá ao aluno sua leitura do texto.

Nesse processo de interlocução, o estudante/leitor age sobre o texto, buscando compreendê-lo e, nesse processo, acontece o encontro entre leitor e autor, mediado pelo texto, conforme já dito, efetivado pelos significados que o estudante construirá ao mobilizar os seus conhecimentos de mundo e de si mesmo, relacionando-os e integrando esses conhecimentos aos aspectos linguísticos e extratextuais para atribuir sentido pela própria leitura. Assim, a interação leitor-texto-autor, a princípio, é facilitada pelo professor, no sentido de criar caminhos e possibilidades para a interação entre sujeitos-texto.

Koch e Elias (2014, p. 37) acrescentam, ainda: "a leitura é uma atividade de construção de sentido que pressupõe a interação autor-texto-leitor, logo, é preciso considerar que, nessa atividade, além das pistas e sinalizações que o texto oferece, entram em jogo os conhecimentos do leitor". Nesse sentido, a leitura não é algo isolado e o sentido do texto não está, propriamente, no texto, mas a leitura é um processo construído a partir da interação do leitor com o autor, mediado pelo texto.

Ao colocar o leitor como foco do processo de construção de sentidos do texto, Koch e Elias (2014, p. 21) abrem uma pertinente discussão acerca da pluralidade de interpretações, pois, segundo elas, ao "considerar o leitor e seus conhecimentos e que esses conhecimentos são diferentes de um leitor para o outro implica aceitar uma pluralidade de leituras e de sentidos em relação a um mesmo texto". Porém, isso não quer dizer que se possa aceitar toda e qualquer interpretação, mas significa entender:

A pluralidade de leituras e de sentidos pode ser maior ou menor dependendo do texto, do modo como foi constituído, do que foi explicitamente revelado e do que foi implicitamente sugerido, por um lado; da ativação, por parte do leitor, de conhecimentos de natureza diversa [...] e de sua atitude cooperativa perante o texto, por outro lado. (KOCH; ELIAS, 2014, p. 22). 
De acordo com o que afirmam Koch e Elias (2014), entendemos que a atividade de leitura depende de dois aspectos, igualmente importantes. Por um lado, da competência de o produtor em organizar linguisticamente o texto, decidindo sobre as informações explícitas e as que podem ser sugeridas, deixando, portanto, implícitas as informações, passíveis de inferência; por outro, entra em jogo a competência do leitor, pois a produção de sentidos dependerá da ativação de conhecimentos diversos, armazenados na memória, e da sua capacidade de realizar inferências.

Assim, ao professor importa saber que a leitura varia de leitor para leitor e que, conforme defende Antunes (2009, p. 202), os sentidos de um texto não estão apenas nos seus aspectos linguísticos, mas resultam de uma "confluência de elementos que estão, simultaneamente, dentro e fora dele". Essa postura pedagógica favorece a construção da cidadania pelo exercício contínuo de atividades de leitura e de escrita que permitam aos alunos o desenvolvimento de competências sociodiscursivas e sua inserção nos diversos espaços sociais de interação.

\section{O processamento textual no ato da leitura}

Como vimos, de acordo com os pressupostos teóricos anteriormente tratados, os sentidos de um texto não estão na sua superfície, na sua estrutura linguística, mas são construídos a partir dos conhecimentos cognitivos do leitor, da sua interação com o texto e com o autor e, também, do contexto de produção. Nesse sentido, o texto só se efetiva na leitura do outro (leitor ou ouvinte), que mobiliza um sistema de conhecimentos para a atribuição de sentidos ao texto que lê ou ouve.

Sendo assim, sob a lupa do processamento textual, apresentamos a seguir algumas questões cognitivas da leitura, afunilando, com destaque, para os conhecimentos cognitivos que analisaremos em atividades interpretativas escritas - de cunho interdisciplinar - realizadas por alunos de um $6^{\circ}$ ano do Ensino Fundamental de uma escola pública da cidade de Petrolina-PE, durante Entretextos, Londrina, v. 19, n. 2, p. 108- 140 / 2019 
as atividades de leitura/escrita-interpretação realizadas nas aulas de Língua Portuguesa, Matemática e Ciências.

Nesse percurso, compreenderemos que, ao lermos um texto, ativamos os modelos armazenados na memória na perspectiva de realizar inferências, levantar hipóteses e construir significados e, a partir da interação com o autor e com o texto, consequentemente, nossos modelos são atualizados, reformulados, ampliando nossos conhecimentos episódicos. Iniciamos nossas reflexões sobre esse assunto, destacando o pressuposto de Koch $(2015$, p. 56$)$ :

No início da leitura ou da conversação, pode acontecer que ainda não tenhamos presente na memória nenhum modelo, de modo que, com a informação do contexto, de um sumário, de um título ou de um anúncio feito pelo interlocutor, fazemos adivinhações sobre os possíveis tópicos ou referentes a serem encontrados no texto. Isto vai permitir a recuperação de modelos de situações similares e a instanciação de frams ou scripts sociais, de modo que a informação deles extraída passará a ser usada para construir o novo modelo.

Percebemos que o contexto sociocognitivo coopera significativamente para a ativação de modelos presentes na memória e para o processamento do texto, o que contribuirá para a compreensão tanto do oral quanto do escrito, como também para a construção de novos modelos que serão armazenados na memória para futuras interações comunicativas. Por essa razão, é fundamental que o professor planeje as atividades de leitura considerando o contexto, os sujeitos de aprendizagem e a situação de uso da linguagem, como também as estratégias de mobilização dos modelos de situações similares para que os alunos possam mobilizar seus conhecimentos na construção de sentidos.

Koch e Elias (2014, p. 57) ressaltam, ainda: "o sentido de um texto não existe a priori, mas é construído na interação sujeitos-texto". Elas asseveram que a interação entre os sujeitos depende muito do contexto sociocognitivo, ou seja, "para que duas ou mais pessoas possam compreender-se mutuamente, é preciso que seus contextos sociocognitivos sejam, pelo menos, parcialmente semelhantes" (KOCH; ELIAS, 2014, p. 61). Isso porque, conforme defendem, cada pessoa já leva consigo seus conhecimentos, sua bagagem cognitiva e, 
nesse processo de interação, "cada um dos parceiros [...] já é, por si mesmo, um contexto", considerando que cada pessoa traz consigo sua cultura, seus costumes, suas experiências e vivências (KOCH; ELIAS, 2014, p. 61). Dessa forma, é importante que na interação, os conhecimentos dos parceiros sejam, pelo menos, em parte, compartilhados, para que um possa compreender 0 outro.

Assim, na atividade de leitura e produção de sentidos, "os parceiros mobilizam diversos sistemas de conhecimentos que têm representados na memória, a par de um conjunto de estratégias de processamento de caráter sociocognitivo e textual" (KOCH, 2016, p. 31). Segundo Koch (2016, p. 32), três grandes sistemas de conhecimentos são mobilizados no processamento textual: o linguístico, o enciclopédico e o interacional.

Esses sistemas, que são ativados pelo processamento textual, estão diretamente ligados à compreensão e produção de sentidos de textos. Para apreendermos como funciona cada um, traremos alguns conceitos e exemplos abordados pelas autoras.

Conhecimento linguístico: É aquele que engloba os conhecimentos lexicais e gramaticais. Com base nesse conhecimento, compreendemos "a organização do material linguístico na superfície do texto; o uso dos meios coesivos para efetuar a remissão ou sequenciação textual; a seleção lexical adequada ao tema ou aos modelos cognitivos ativados" (KOCH; ELIAS, 2014, p. 40). Em suma, é esse conhecimento que possibilita toda a organização linguística na superfície do texto, sendo, portanto, o "responsável pelo somsentido" (KOCH, 2016, p. 32).

Conhecimento enciclopédico ou conhecimento de mundo: É aquele, segundo Koch (2016), que está armazenado na memória de cada pessoa, quer do tipo declarativo (fatos do mundo), quer do tipo episódico ("os modelos cognitivos" socioculturalmente determinados e adquiridos através da experiência). Koch (2016, p. 32) explica que é com base nesses modelos cognitivos que "se levantam hipóteses [...]; que se criam expectativas sobre o(s) campo(s) lexicais a ser(em) explorado(s) no texto; que se produzem as Entretextos, Londrina, v. 19, n. 2, p. 108- 140 / 2019 
inferências que permitem suprir as lacunas ou incompletudes encontradas na superfície textual". Portanto, na leitura de um texto ou na interação social são ativados os conhecimentos de ordem geral e pessoal, armazenados na memória para a compreensão e produção de sentidos. A ausência desse conhecimento compromete diretamente a compreensão e produção de sentidos.

Conhecimento sociointeracional: Diz respeito às formas de interação por meio da linguagem. Segundo Koch (2015, p. 58), "é o conhecimento sobre as ações verbais, isto é, sobre as formas de inter-ação através da linguagem" e abrange quatro tipos de conhecimentos: ilocucional, comunicacional, metacomunicativo e superestrutural:

a) Conhecimento ilocucional: é o tipo de conhecimento que possibilita reconhecer os objetivos ou propósitos pretendidos pelo produtor do texto, numa situação específica de interação (KOCH; ELIAS, 2014, p. 46). A ativação desse conhecimento possibilita ao aluno realizar inferências na perspectiva de identificar os objetivos pretendidos pelo autor do texto. Esse conhecimento é ativado sempre que o professor leva o aluno a descobrir qual a intenção do autor ao produzir tal texto.

b) Conhecimento comunicacional: refere-se às normas aplicadas à comunicação, ligadas diretamente à recuperação dos objetivos do autor do texto, à seleção da variação linguística, à adequação das sequências textuais, dos gêneros a cada situação comunicativa. Portanto, muitas vezes, o autor competente se utiliza de conhecimentos comunicacionais, tais como, uso da variedade linguística, adequação do gênero, entre outros, para subverter e descumprir tais normas a fim de alcançar determinado objetivo.

c) Conhecimento metacomunicativo: permite ao autor do texto evitar conflitos de interpretação (on-line ou a posteriori) a fim de garantir a compreensão do texto e a aceitação dos objetivos de produção por parte do interlocutor através de ações linguísticas. O domínio desse 
conhecimento possibilita ao aluno a melhoria da competência de produção textual, pois busca evitar conflitos de interpretação no processo de interação verbal.

d) Conhecimento superestrutural ou conhecimento sobre os gêneros textuais: esse é o conhecimento de modelos textuais globais que possibilita "reconhecer textos exemplares de determinado gênero ou tipo, envolve, também, conhecimentos sobre as macrocategorias ou unidades globais, que distinguem os vários tipos de textos, sobre a sua ordenação ou sequenciação [...]" (KOCH, 2016, p. 33). Portanto, as características, relativamente estáveis do gênero, adquiridas pela competência metagenérica, permitem ao leitor reconhecer o gênero, ativando o conhecimento superestrutural. Quando as estratégias cognitivas mobilizam esse conhecimento, o estudante/leitor reconhece o gênero textual a que pertence o texto em estudo, por meio da representação textual (RT) que tem na memória, fazendo associações e integrando conhecimentos, confrontando informações arquivadas na memória com as novas situações de uso da linguagem.

Tais mobilizações de conhecimentos são realizadas a partir de estratégias de processamentos textuais que o leitor/escritor-falante/ouvinte utiliza nas interações socioculturais humanas. Segundo Koch (2016), essas estratégias realizam a mobilização "on-line" dos sistemas de conhecimento, possibilitando, assim, a compreensão e a produção de sentidos dos textos (orais ou escritos). A autora classifica essas estratégias em cognitivas, textuais e sociointeracionais.

Estratégias cognitivas. Koch (2016) as define como estratégias que consistem em hipóteses operacionais eficazes sobre a estrutura e o significado de um fragmento de texto ou de um texto inteiro. Elas fazem parte do nosso conhecimento geral, representando o conhecimento procedural que possuímos sobre compreensão de discurso. 
Estratégias sociointeracionais. são aquelas responsáveis pela interação entre os sujeitos sociais. Segundo Koch (2016, p. 36-37), as estratégias interacionais são "socioculturalmente determinadas que visam a estabelecer, manter e levar a bom termo uma interação verbal". Para isso, utiliza-se de negociações, de atenuações, de estratégias de polidez e identificam causas de mal-entendidos com a intenção de corrigi-los para garantir o sucesso da interação.

Estratégias textuais: são definidas como aquelas que "dizem respeito às escolhas textuais que os interlocutores realizam, desempenhando diferentes funções e tendo em vista a produção de determinados sentidos" $(\mathrm{KOCH}, 2016$, p. 38). Ainda sustenta Koch (2016) que tais estratégias não deixam de ser interacionais e cognitivas.

Como observamos, levando em consideração o trabalho pedagógico no ambiente escolar, há uma relação extremamente complexa entre conhecimentos e estratégias que estão diretamente envolvidos nas ações cognitivas de leitura, de escrita e de interpretação textuais. Nossa intenção será exatamente entender como funcionam essas questões em atividades interdisciplinares desenvolvidas dentro da sala de aula.

\section{O caminho metodológico da intervenção didática}

Tendo em vista que o projeto de intervenção didático-pedagógico pensado para esta investigação se desenvolveu num contexto escolar, a partir da realidade e com a participação dos sujeitos pesquisadores, adotamos um trabalho qualitativo, inserido numa pesquisa-ação que envolveu os agentes do processo ensino-aprendizagem, com a finalidade de aprimorar as habilidades da leitura e interpretação de textos dos alunos. Conforme aponta Tripp (2005, p. 447), a pesquisa-ação seria "uma forma de investigação-ação que utiliza técnicas de pesquisa consagradas para informar a ação que se decide tomar para melhorar a prática". O autor ainda deixa claro que "A pesquisa-ação educacional é principalmente uma estratégia para o desenvolvimento de Entretextos, Londrina, v. 19, n. 2, p. 108- 140 / 2019 
professores e pesquisadores de modo que eles possam utilizar suas pesquisas para aprimorar seu ensino e, em decorrência, o aprendizado de seus alunos" (TRIPP, 2005, p. 445).

Como professores de Língua Portuguesa, temos observado uma forte reprodução de práticas em que, ainda, as aulas de leitura têm-se limitado ao treinamento à decodificação, num exercício de pura fruição fonética; de lado paralelo, vemos a questão da escrita-interpretativa enquanto resposta a questões que visam, tão somente, constatar se o estudante leu o texto, levando-o a identificar informações de superfície ou de mera localização, o que pouco contribui para a formação do leitor competente, no exercício de sua cidadania.

Assim, por defendermos o papel social da leitura e sua importância no processo da aprendizagem do aluno, adotamos um projeto de leitura e interpretação de textos, na perspectiva interdisciplinar, desenvolvido por meio da pesquisa-ação, visando, sobretudo, aprimorar o processo do ensino da leitura e ampliar as habilidades dos estudantes, a partir dos conhecimentos mobilizados pelas estratégias cognitivas do processamento textual. Essas práticas escolhidas e colocadas em ação vêm apoiar-se, fundamentalmente, na concepção de sequências de aplicação de atividades e de práticas didáticas, por considerarmos que as etapas de leitura-escrita-interpretação formam "um conjunto de atividades escolares organizadas, de maneira sistemática, em torno de um gênero textual oral ou escrito" (DOLZ; NOVERRAZ; SCHNEUWLY, 2004, p. 97).

Tal atitude de utilização da interdisciplinaridade, dentro de uma perspectiva de ensino-aprendizagem a partir de sequências pedagógicas de leitura/escrita/interpretação de atividades, faz entendermos a ação interdisciplinar como algo que "se impõe também tanto para a formação do homem quanto para responder às necessidades da ação" (JAPIASSU, 1976, p. 29). Ora, essa junção múltipla de conhecimentos dos docentes foi primordial para que as ações múltiplas e complexas das atividades funcionassem em cada uma das disciplinas no contexto da escola; até porque é necessário entender Entretextos, Londrina, v. 19, n. 2, p. 108- 140 / 2019 
que a interdisciplinaridade é uma "atitude de ousadia" que busca frente e força "diante dos conhecimentos", cabendo pensar aspectos que envolvem "a cultura do lugar onde se formam e se encontram os professores" (FAZENDA, 2008, p. 17).

Nesse sentido, foi o projeto aplicado em uma escola pública estadual da cidade de Petrolina- $\mathrm{PE}$, abrangendo tanto a prática quotidiana quanto a pesquisa acadêmico-qualitativa, integrando teoria e prática, que teve início após a socialização dos resultados da escola sobre o desempenho dos estudantes na avaliação externa nas áreas de Língua Portuguesa e de Matemática, resultados esses que apresentaram diversos problemas em relação à interpretação textual. Isso nos despertou para a necessidade de intervir na base, considerando que a escola é prioritariamente Fundamental, pois oferta educação para crianças e jovens do $6^{\circ}$ ao $9^{\circ}$ ano. Para isso, elaboramos uma atividade diagnóstica para os estudantes do $6^{\circ}$ ano com a finalidade de levantar o perfil de leitura da turma que seria alvo dessa investigação. Após esse diagnóstico, apresentamos aos professores da escola a proposta de intervenção, sob o eixo da leitura interdisciplinar.

A aplicação de atividades de leitura e interpretação de textos, integrando três disciplinas do currículo, Língua Portuguesa (LP), Matemática e Ciências, com foco no processamento textual, constou de quatro etapas: a primeira, atividade diagnóstica; a segunda, as oficinas pedagógicas, constantes de espaços de discussões, reflexões e construção das atividades de leitura interdisciplinar; a terceira, a aplicação das atividades de leitura nas três disciplinas curriculares e, por fim, a análise do corpus da pesquisa. Os professores envolvidos discutiram temas, nas oficinas pedagógicas, oriundos do contexto escolar, e, a partir desses temas e de gêneros textuais diversos, elaboraram as atividades de leitura tal qual o percurso das etapas do seu desenvolvimento, fundamentando-se nos gêneros trazidos, sempre traçando a elaboração de atividades a partir do mesmo texto para as três disciplinas, cada qual com suas questões específicas. Isso nos fez compreender que, 
Criar contextos de produção precisos, efetuar atividades ou exercícios múltiplos e variados: é isso que permitirá aos alunos apropriarem-se das noções, das técnicas e dos instrumentos necessários ao desenvolvimento de suas capacidades de expressão oral e escrita, em situações de comunicação diversas. (DOLZ; NOVERRAZ; SCHNEUWLY, 2004, p. 96).

Nessa abordagem, destacamos, como o fazem os autores, a importância de oportunizar aos estudantes o acesso a contextos de produção por meio da aplicabilidade de atividades diversificadas de forma a aprimorar as suas capacidades de uso da linguagem, ação esta que buscamos desenvolver a partir da integração de disciplinas e dos conhecimentos por meio do texto: objeto de ensino nas três áreas do currículo.

Ressaltamos, ainda, que durante a aplicação do projeto, toda a escola foi mobilizada para a leitura, por meio das oficinas pedagógicas que ora integrava apenas os professores das três disciplinas envolvidas, ora integrava todo 0 corpo docente para a elaboração de atividades de leitura para todos os alunos, por meio do dia " $D$ " da leitura na escola.

Nesse percurso, trabalhamos três atividades de leitura a partir de três diferentes gêneros (mas destacamos neste artigo dois dos gêneros trabalhados), possibilitando aos estudantes a leitura do mesmo texto sob o viés da Matemática, da Ciência e da LP, ou seja, três focos diferentes sobre o mesmo texto, apresentando abordagens e metodologias diversificadas, o que tornou as atividades globais e dinâmicas.

Embora tenhamos colhido um corpus de 105 (cento e cinco) atividades de cada disciplina curricular, por conta do espaço de que dispomos neste artigo, apresentaremos um singelo recorte da pesquisa, enfatizando as atividades de leitura, nos textos 01 e 02, de duas alunas (A e B), selecionadas a partir dos critérios assiduidade e participação nas três disciplinas envolvidas no projeto, sob o consenso das professoras partícipes, destacando uma questão de cada disciplina curricular com o objetivo de reconhecermos e entendermos o funcionamento dos conhecimentos cognitivos quando essas alunas do $6^{\circ}$ ano 
respondem às atividades de leitura e interpretação nesse movimento interdisciplinar.

\section{As atividades e o processamento cognitivo da interpretação}

Nesta seção, vamos analisar as atividades realizadas, observando como funcionam os conhecimentos e o processamento cognitivo na interpretação de algumas questões respondidas pelas alunas. Apresentaremos, primeiro, o texto que serviu de base para as três disciplinas, e, logo depois, algumas questões específicas em cada uma delas, com as correspondentes respostas colocadas pelas alunas.

\section{Atividade $01^{4}$}

${ }^{4} \mathrm{O}$ espaço não nos permite trazer todas as questões produzidas de todas as atividades. Por isso temos que realizar o devido recorte, apresentando apenas as questões analisadas. 
Imagem 1- Texto base 01 para as atividades

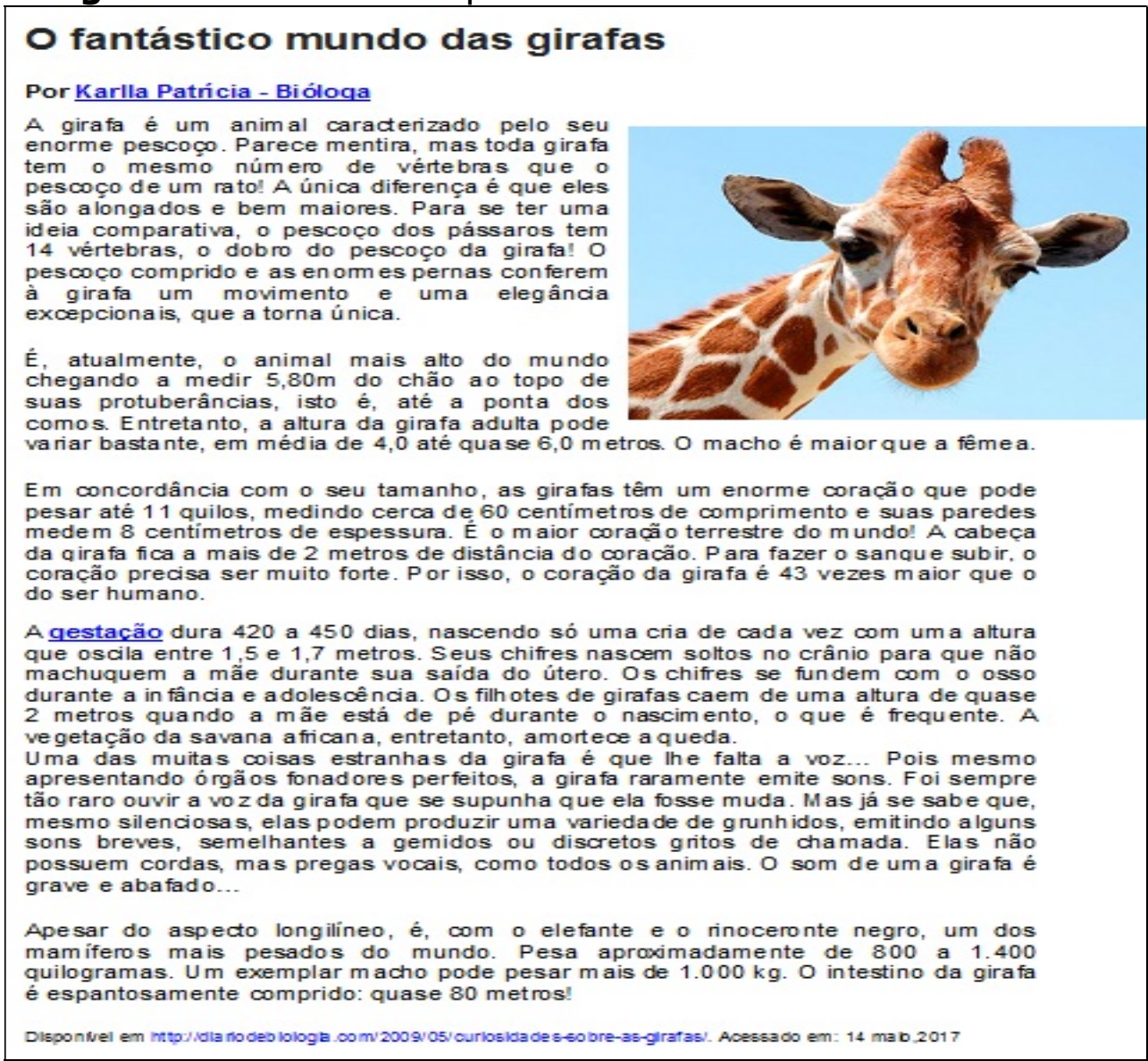

Questão no 02 da atividade de Matemática - resposta dada pela Aluna A

02. De acordo com o texto, o pescoço de um pássaro possu (14) vértebras, o dobro do pescoço da girafa. Quantas vértebras possui o pescoço da girafa?

Questão nº 02 da atividade de Matemática - resposta dada pela Aluna B

02. De acordo com o texto, o pescoço de um pássaro possui 14 vértebras, o dobro do pescoço da girafa. Quantas vértebras possui o pescoço da girafa? girafa? $20 x$ teleres.

Para responder à questão no 02 de Matemática, as alunas A e B precisaram, primeiramente, mobilizar os conhecimentos linguísticos, condição básica para a leitura e compreensão da questão, realizando, a priori, a 
decodificação da informação, que trata do contato superficial com a organização lexical do texto. Sem esse conhecimento cognitivo linguístico, a interpretação fica comprometida, pois é esse conhecimento que abre caminho para a mobilização dos demais sistemas de conhecimento, tal como o enciclopédico, fundamental para a interpretação da questão em destaque.

Enquanto o conhecimento linguístico aponta para a superfície do texto e para a interação sujeitos-texto, é o conhecimento enciclopédico ou de mundo que possibilita ao leitor/aluno responder à questão em tela, ativando conhecimentos escolares armazenados na memória. Observamos que há uma declaração, afirmando que o pescoço de um pássaro possui 14 vértebras. E esse número corresponde ao dobro do número de vértebras do pescoço da girafa. Para saber o que é dobro, o leitor/aluno precisa ativar um conhecimento adquirido na escola. Trata-se, portanto, de conhecimento da "cultura humana escolar" (DIKSON; ROCHA, 2015, p. 8).

Nesse contexto, a aluna $B$ aciona 0 conhecimento adquirido culturalmente na escola, pois se 14 representa o dobro de " $x$ ", então " $x$ " é a metade de 14 , o que the possibilita responder com precisão a referida questão. Já a aluna $A$, embora tenha dado uma resposta diferente para a mesma questão e, aparentemente não tenha armazenado tal conhecimento, ao registrar o número 28 como resposta para a pergunta, demonstra ter construído o conceito exigido pela referida questão, mas não atende à resposta esperada, pois o dobro que a aluna A mencionou foi do número 14, ou seja, ela realizou uma multiplicação ao invés de uma divisão pelo numeral 2 , comprometendo o atendimento à questão, o que demonstra um problema ou de leitura (conhecimento linguístico) ou de interpretação (dentro do conhecimento enciclopédico).

Acerca do mesmo texto, "O fantástico mundo das girafas", agora em Ciências, destacamos a questão 02 da atividade construída pela professora da disciplina: 
Questão no 02 da atividade de Ciências - resposta dada pela Aluna A

\section{A girafa é um animal vertebrado ou invertebrado?}

Questão nº 02 da atividade de Ciências - resposta dada pela Aluna B

02. A girafa é $\mathrm{um}$ animal vertebrado ou invertebrado?

verteriado

Semelhantemente à questão de Matemática, além do conhecimento linguístico, necessário para entender à questão, que vai desde a decodificação até a organização lexical do texto, observamos que é dada ao leitor/aluno, na organização da pergunta, a opção de escolher entre vertebrado ou invertebrado, dois termos interligados pela conjunção "ou" que processa na mente a possibilidade de escolha entre um e outro termo. Mas, fazer a opção exige do leitor/aluno o conhecimento enciclopédico, adquirido na escola, que irá interagir com as informações presentes no texto, de forma que o acesso às atividades de Matemática antes da atividade de Ciências, conforme aponta a questão 02, aqui analisada, possibilitou a integração e a mobilização de conhecimentos já armazenados na memória, levando as alunas $\mathrm{A}$ e $\mathrm{B}$ a optarem pela resposta correspondente ao que a professora, certamente, explicou em aulas anteriores. Ou seja, ambas reconheceram escolar-culturalmente o que significaria "vertebrado" e "invertebrado", escrevendo a resposta condizendo à correta da questão.

Finalizando essa primeira atividade, abordaremos a seguir a questão 01 de LP, última disciplina curricular a trabalhar com o texto da girafa:

Questão no 01 da atividade de Língua Portuguesa - resposta dada pela Aluna A

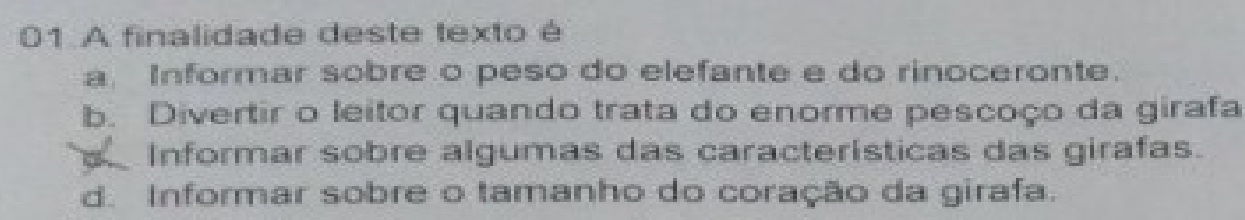


Questão no 01 da atividade de Língua Portuguesa - resposta dada pela Aluna B

01. A finalidade deste texto é

a. Informar sobre o peso do elefante e do rinoceronte.

b. Divertir o leitor quando trata do enorme pescoço da girafa.

* Informar sobre algumas das características das girafas.

d. Informar sobre o tamanho do coração da girafa.

Na questão em destaque, observa-se que, para respondê-la, as alunas A e B mobilizaram, possivelmente, as mesmas estratégias cognitivas. Nota-se que precisaram, antes de tudo, ler integralmente o texto, eliminar possibilidades, a partir do conhecimento linguístico sobre o gênero textual, pois se trata de um gênero veiculado em jornais, revistas ou sites de internet com o propósito de informar e não de divertir.

Mobilizando esse conhecimento sociointeracional que diz respeito, principalmente, ao conhecimento superestrutural ou conhecimento sobre 0 gênero, as alunas A e B conseguem eliminar a alternativa " $B$ ", restando as alternativas " $A$ ", " $C$ " e "D", que apontam para o objetivo que é INFORMAR. Portanto, para que as alunas A e B marcassem a alternativa " $C$ ", elas eliminaram a alternativa " $A$ ", muito possivelmente pela ausência de informação sobre rinoceronte no decorrer do texto, por tratar apenas de questões relativas ao animal girafa. Há, portanto, uma inconsistência de informação na alternativa " $A$ ", o que os conhecimentos de mundo e interacional permitem asseverar.

Ao comparar, então, as alternativas " $C$ " e " $D$ ", é possível que as alunas $A$ e $B$ tenham percebido que embora o texto aborde, em determinada passagem, sobre o tamanho do coração da girafa, isso não é a finalidade do texto, pois estaria minimizando-o e restringindo-o a apenas uma das características informadas e, considerando que o texto trata de várias características da girafa e não apenas de uma, as alunas A e B optam por marcar a alternativa " $\mathrm{C}$ ", que é mais abrangente.

As alunas ativam, dessa maneira, o conhecimento interacional, articulando conhecimentos do tipo ilocucional, quando buscam compreender o objetivo ou finalidade da autora do texto; e superestrutural, ao mobilizar Entretextos, Londrina, v. 19, n. 2, p. 108- 140 / 2019 
conhecimento sobre o gênero em questão que possui o fito de informar ao leitor sobre dado assunto. Ativam também o conhecimento linguístico, pois conseguem articular as questões de textualidade desde o início da leitura; bem como o conhecimento enciclopédico, pois precisam delimitar o que a letra " $\mathrm{C}$ " pede, isto é, é necessário ter conhecimento do que seja "características", do que seja "informar" essas "características", e, mais ainda, "informar" essas "características" de um determinado animal chamado "girafa". Ou seja, ativando os três conhecimentos, simultaneamente, através de determinadas estratégias cognitivas, as alunas executam corretamente uma ação interpretativa, o que as leva a escolherem adequadamente a alternativa da questão pretendida pela professora de LP.

\section{Atividade 02}

Imagem $\mathbf{2}$ - Texto base 02 para as atividades

Quase $18 \%$ dos alunos dizem sofrer bullying no Brasil, aponta estudo

No Brasil, aproximadamente um em cada dez estudantes é vítima frequente de bullying nas escolas. São adolescentes que sofrem agressões físicas ou psicológicas, que são alvo de piadas e boatos maldosos, excluídos propositalmente pelos colegas, que não são chamados para festas ou reuniões. O dado faz parte do terceiro volume do Programa Internacional de Avaliação de Estudantes (Pisa) 2015 , dedicado ao bem-estar dos estudantes.

O relatório é baseado na resposta de adolescentes de 15 anos que participaram da avaliação. No Brasil, 17,5\% disseram sofrer alguma das formas de bullying "algumas vezes por mês"; 7,8\% disseram ser excluídos pelos colegas; 9,3\%, ser alvo de piadas; $4,1 \%$, serem ameaçados; $3,2 \%$, empurrados e agredidos fisicamente.

Outros 5,3\% disseram que os colegas frequentemente pegam e destroem as coisas deles e 7,9\% são alvo de rumores maldosos. Com base nos relatos dos estudantes, $9 \%$ foram classificados no estudo como vítimas frequentes de bullying, ou seja, estão no topo do indicador de agressões e mais expostos a essa situação.

A publicação faz parte das divulgações do último Pisa, de 2015, avaliação aplicada pela Organização para a Cooperação e Desenvolvimento Econômico (OCDE).

Participaram dessa edição 540 mil estudantes de 15 anos que, por amostragem, representam 29 milhões de alunos de 72 países. São 35 países-membros da OCDE e 37 economias parceiras, entre elas o Brasil.

Em comparação com os demais países avaliados, o Brasil aparece com um dos menores "índices de exposição ao bullying". Em um ranking de 53 países com os dados disponíveis, o Brasil está em $43^{\circ}$.

Fonte: Tokarnia (2017). 
Questão no 04 da atividade de Matemática - resposta dada pela Aluna A

04. No ranking geral, qual a posição que o Brasil ocupa entre os 53 paises sobre a exposição ao bullying? Essa colocação, em comparação aos 10 primeiros paises, é boa ou ruim? Por quê?

43 boar pia nas nomon entre no piotuen paisen

Questão no 04 da atividade de Matemática - resposta dada pela Aluna B

04. No ranking geral, qual a posiçăo que o Brasil ocupa entre os 53 paises sobre a exposiçăo ao bullying? Essa colocação, em comparação aos 10 primeiros paises, é boa ou ruim? Por quê?

43.2

inces, entar

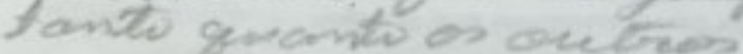

Para responder à questão 04 de Matemática, do texto sobre o bullying, as alunas A e B precisam ter bastante atenção, pois a questão traz, ao mesmo tempo, três questionamentos. Assim, precisam ativar, primeiramente, na memória, o que já ouviram falar sobre ranking, um conhecimento linguístico, mas também enciclopédico, por se tratar de uma palavra ligada ao léxico das pesquisas estatísticas em que procuram apontar os melhores e, consequentemente, os piores em determinada avaliação. Porém, a ausência desse conhecimento não chega a prejudicar o atendimento à questão, considerando a clareza da pergunta ao solicitar a "posição" ocupada pelo Brasil em relação aos 53 países avaliados sobre a exposição ao bullying. Essa é a primeira resposta dada pelas alunas ao registrarem "43", uma informação que se encontra na superfície do texto, como podemos notar no último parágrafo: "Em um ranking de 53 países com dados disponíveis, o Brasil está em 430". Para tanto, as alunas mobilizaram estratégias linguísticas, embasadas na decodificação e identificação de informações explícitas.

Já a segunda pergunta, desta mesma questão, está diretamente relacionada à terceira que exige das alunas uma interpretação dos fatos. Observamos que as alunas A e B, ao responderem "boa", estão se referindo à posição ocupada pelo Brasil no ranking de exposição ao bullying. Essa resposta 
exigiu delas a capacidade de realizar inferência, por meio das estratégias cognitivas que mobilizam o conhecimento enciclopédico, que se refere a conhecimentos adquiridos na escola ou na vida, em contato com outras pessoas ou na sua relação com o mundo, pois trata de uma temática bastante discutida na escola, na sociedade e divulgada pelos meios de comunicação e de informação. Essa interpretação revela, portanto, uma posição crítica das alunas, pois, normalmente, o que percebemos nesse tipo de pesquisa é que aquele que ocupa os últimos lugares nas estatísticas, geralmente, está entre os piores. No caso da pesquisa abordada no texto, não está entre os 10 primeiros países no ranking, ou seja, não ocupar uma posição próxima do último lugar revela pouca exposição ao bullying, o que é extremamente positivo.

Questão da atividade de Língua Portuguesa - resposta dada pela Aluna A

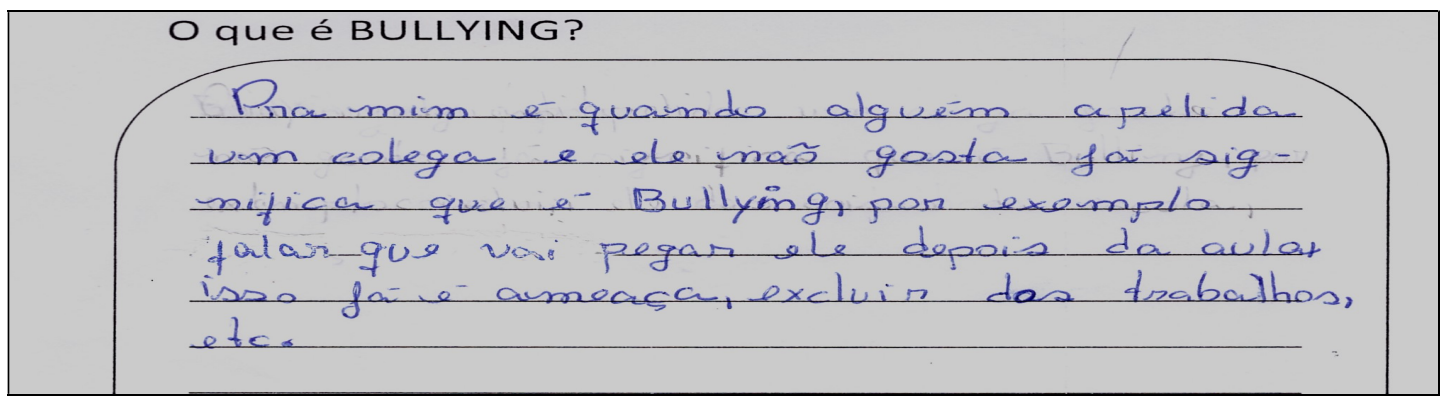

Questão da atividade de Língua Portuguesa - resposta dada pela Aluna B

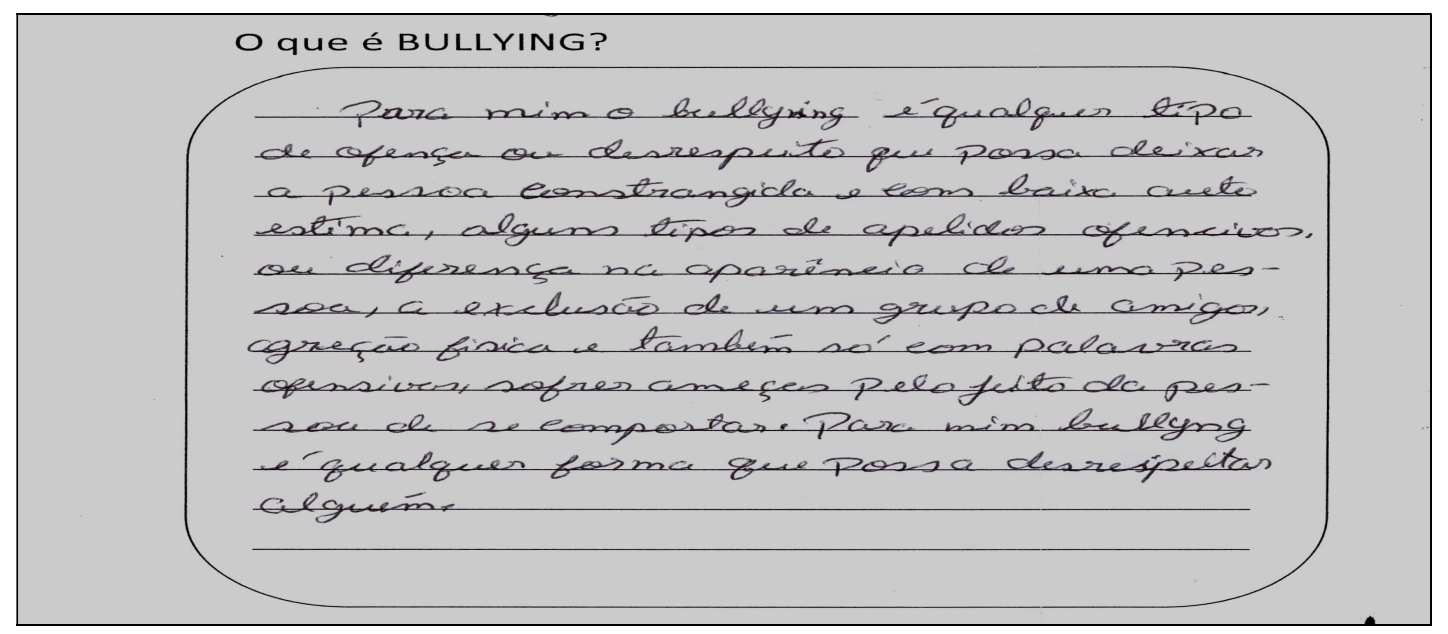


Ao produzir resposta à pergunta "O que é bullying?", a aluna $A$ mobilizou estratégias cognitivas de conhecimento linguístico para organizar a estrutura textual e selecionar o léxico de acordo com a temática, empregando, também, elementos coesivos de referenciação, tais como, "ele" (linhas 2 e 4) e "isso" (linha 5), mas todo esse conhecimento somente está disponível na memória porque a aluna A teve acesso ao conhecimento adquirido na escola, o que caracteriza o conhecimento enciclopédico.

Além desses conhecimentos, observamos que a aluna inicia sua resposta explicando o termo por meio da exemplificação, uma característica do conhecimento sociointeracional. Notamos que, para ser mais enfática, a aluna $A$ procura esclarecer seu ponto de vista ao exemplificar o que vai além do bullying, afirmando "falar que vai pegar ele depois da aula, isso já é ameaça...", o que enfatiza com o termo "já", ou seja, quando a aluna A diz que "isso já é ameaça", ela ressalta que a ameaça ultrapassa o bullying.

Na produção da aluna $B$, observamos que, diferentemente da aluna $A$, ela inicia conceituando o bullying. Para isso, mobiliza os conhecimentos linguísticos, considerando a seleção lexical e os termos coesivos presentes no texto. Em seguida, mobiliza questões metacognitivas, através da estratégia de formulação, utilizando-se de exemplos com a finalidade de evitar qualquer tipo de conflito na comunicação, garantindo a compreensão do texto e a aceitação do parceiro (professor) do conceito que está construindo.

Dessa forma, as alunas A e B, ao produzirem respostas à questão, mobilizam os três sistemas de conhecimento. Porém, nesse processamento cognitivo, cada aluna utiliza com mais ênfase determinadas estratégias cognitivas em detrimento de outras, o que podemos constatar nas próprias respostas. A aluna A busca sustentação mais nos conhecimentos de mundo, portanto, enciclopédicos; já a aluna $B$ ativa, com grande ênfase, os três sistemas de conhecimento, nitidamente, o linguístico e o sociointeracional, mas também não deixa de ativar o conhecimento enciclopédico na medida em que a construção de conceito somente é possível pelos conhecimentos acumuláveis e retidos na memória, adquiridos por meio das experiências pessoais, Entretextos, Londrina, v. 19, n. 2, p. 108- 140 / 2019 
experimentadas ao longo da vida, como também dos conhecimentos escolarizados.

Por fim, a questão 05 de Ciências que traz no corpo da questão dois comandos.

Questão da atividade de Ciências - resposta dada pela Aluna A

05. Você já sofreu bullying ou já presenciou alguma cena na escola? Comente

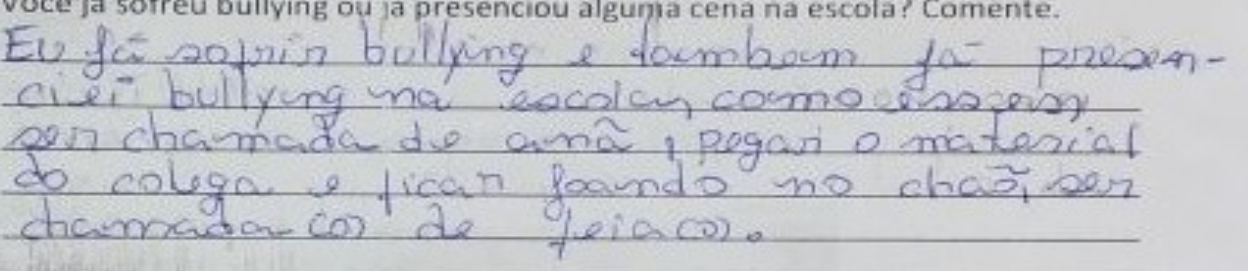

Questão da atividade de Ciências - resposta dada pela Aluna B

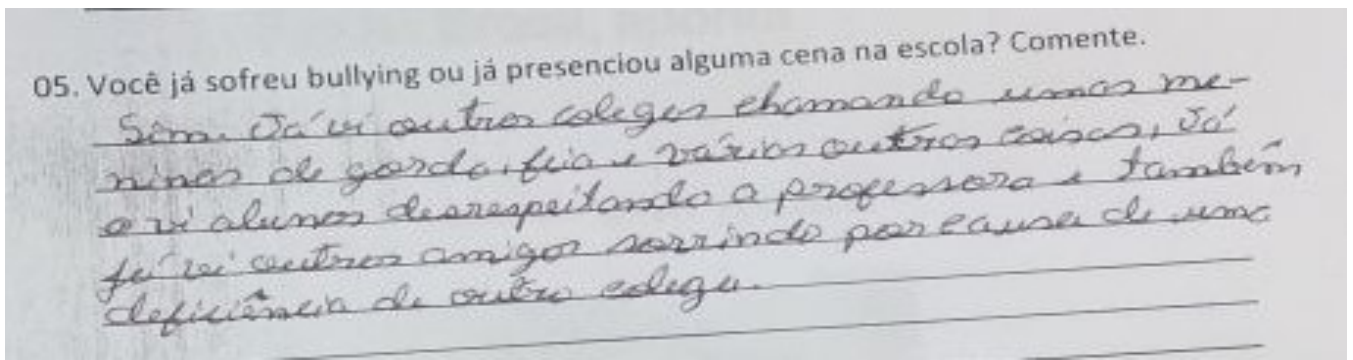

Na questão 05 de Ciências, há dois comandos: primeiramente, pergunta se já sofreu ou presenciou alguma cena de bullying, em seguida, solicita-se que comente sobre isso. Observamos que é condição para responder à questão, principalmente, a ativação de conhecimentos ligados à experiência das alunas, portanto, conhecimentos do tipo episódico, socioculturalmente determinados e construídos a partir de vivências. Esse conhecimento enciclopédico está diretamente relacionado às experiências de interação social vividas pelas alunas $A$ e $B$, o que colabora imensamente para responderem à questão, pois faz com que elas (re)visitem as cenas já presenciadas ou vividas, construídas nessas relações sociointeracionais.

A aluna " $A$ ", ao afirmar que já sofreu e presenciou cenas de bullying, busca, na memória, fatos que comprovem seu argumento, embora não ligue esses fatos diretamente a ela, mas que possam ter acontecido tanto com ela 
quanto com outras pessoas. Já a aluna " $B$ " afirma ter presenciado cenas na escola relacionadas à temática e ativa na memória esses fatos. Para organizar esses fatos que buscam na memória, as alunas A e B precisam ativar outro conhecimento que é o linguístico, responsável pela organização textual e seleção lexical ligada à temática. Portanto, para que ambas as alunas respondam com eficiência à questão, como o fizeram, são ativadas estratégias cognitivas que, perpassando tanto pelos conhecimentos linguístico, tanto mais ainda pelos enciclopédicos ou de mundo.

\section{Considerações Finais}

Depois das análises realizadas, compreendemos que toda a resposta produzida para atender a uma determinada pergunta, somente é possível por meio da interação entre sujeitos-texto, viabilizada pelo conhecimento sociointeracional que é responsável pelas ações verbais. Considerando também que toda a interação somente se realiza através da linguagem, então, para produzir uma resposta o leitor/aluno precisa ativar além do conhecimento interacional, o conhecimento linguístico que responde por toda a organização textual, coesão e coerência e seleção lexical, organizada coerentemente para corresponder à temática do texto.

Integrando esses sistemas, o leitor/aluno ainda ativa, com maior ou menor ênfase, estratégias de conhecimentos adquiridos na escola ou advindos da sua relação com o mundo ou com o outro, das suas experiências pessoais, é o que chamamos de conhecimentos enciclopédicos. Tudo isso nos leva a afirmar que, em qualquer questão que envolva pergunta e resposta, haverá sempre a mobilização dos três grandes sistemas de conhecimento. Ler e interpretar textos dependem, em grande parte, da capacidade de mobilizar conhecimentos armazenados, como também da sua disponibilidade na memória.

Essa experiência interdisciplinar - sustentada e desenvolvida através de uma pesquisa possibilitada pelo Mestrado Profissional/PROFLETRAS -, com as Entretextos, Londrina, v. 19, n. 2, p. 108- 140 / 2019 
análises que propusemos, fez-nos perceber duas questões de extrema importância. A primeira é que 0 trabalho envolvendo múltiplos professores/disciplinas na sala de aula, tendo o gênero textual-discursivo como lugar de partida, através de leitura-escrita-interpretação, é um caminho extremamente valioso para compreender de que maneira funcionam os processamentos textuais e as estratégias de leitura e interpretação dos alunos; e a segunda, indubitavelmente, é entender que estamos carecendo de bem mais ações que integrem projetos pedagógicos e didáticos que procurem melhorar substancialmente as competências linguísticas de leitura, de interpretação e de escrita das crianças do Fundamental, tendo em vista que, infelizmente, as séries de base parecem não receber a atenção que deveriam no Brasil.

Além do mais, o ganho pedagógico de ações interventivas como as que propomos nesta pesquisa - em especial por ter um caráter de pesquisa-ação -, que aponta para análises de estratégias cognitivas de leitura-escrita de crianças em sala de aula, nos encaminha a um processo reflexivo de, a partir das atividades e das respostas escritas, procurar compreender como se dá essa sistematização interpretativa dos alunos e, em especial, quais estratégias e processamentos textuais são mais [ou menos] ativados durante a execução das interpretações - o professor/pesquisador com essa série de dados, tem possibilidade bem mais robusta de enxergar problemas de leitura/escrita/interpretação em sua turma, ficando bem mais consistente e possível traçar estratégias/atividades que ataquem diretamente aquelas ações cognitivas que precisam ser mais bem trabalhadas em interpretação na leituraescrita dos alunos.

O certo é que devemos, sempre, na qualidade de professores e pesquisadores no campo das Letras, com atitudes docentes e pedagógicas contundentes e interventivas, lutar para que esses espaços sejam cada vez mais preenchidos de fazeres pedagógicos reais e que funcionem no contexto sócio-histórico-cultural dos sujeitos-alunos, até porque, ler, escrever e 
interpretar não são ações exclusivas da/na escola, mas, antes de tudo, perpassam por movimentos de cidadania, direito de todos.

\section{Referências}

ANTUNES, Irandé. Aula de português. encontro \& interação. São Paulo:

Parábola Editora, 2003.

ANTUNES, Irandé. Língua, texto e ensino: outra escola possível. São Paulo: Parábola Editora, 2009.

BAKHTIN, Mikhail. Estética da criação verbal. São Paulo: Martins Fontes, 1992.

BAZERMAN, Charles. Escrita, Gênero e interação social. São Paulo: Editora Cortez, 2007.

CAFIERO, Delaine. Letramento e leitura: formando leitores críticos. In: ROJO, Roxane (org.). Explorando o ensino: língua portuguesa. Brasília, DF: PDE, 2010.

DIKSON, Dennys; ROCHA, Macicleide Barros da. A linguística de texto e o processamento textual de tirinhas do Enem. Linguagem, São Carlos, v. 24, n. 1, 2015. versão online. Disponível em:

http://www.linguasagem.ufscar.br/index.php/linguasagem/article/view/103/pdf _5. Acesso em: 30 jan. 2017.

DOLZ, Joaquim; NOVERRAZ, Michele; SCHNEUWLY, Bernard. Sequências didáticas para o oral e a escrita: apresentação de um procedimento. In: DOLZ, Joaquim; SCHNEUWLY, Bernard. Gêneros orais e escritos na escola. Tradução e organização de Roxane Rojo e Glaís Sales Cordeiro. Campinas, SP: Mercado de Letras, 2004. p. 81-108.

FAZENDA, Ivani, Catarina Arantes. O que é interdisciplinaridade? São Paulo: Cortez, 2008.

GERALDI, João Wanderley (org.). O texto na sala de aula. São Paulo: Anglo, 2012.

JAPIASSU, Hiton. Interdisciplinaridade e patologia do saber. Rio de Janeiro: Imago, 1976.

KOCH, Ingedore G. Villaça. Desvendando os segredos do texto. 8. ed. São Paulo: Cortez, 2015.

KOCH, Ingedore G. Villaça. O texto e a construção dos sentidos. 10. ed. São Paulo: Contexto, 2016. 
KOCH, Ingedore G. Villaça; CUNHA-LIMA, Maria Luiza. Do cognitivismo ao sociocognitivismo. In: MUSSALIM, Fernanda; BENTES, Anna Christina (org.). Introdução à linguística: fundamentos epistemológicos. São Paulo: Cortez, 2005. v. 3, p. 251-300.

$\mathrm{KOCH}$, Ingedore G. Villaça; ELIAS, Vanda Maria. Ler e compreender: os sentidos do texto. 3. ed. São Paulo: Contexto, 2014.

MARCUSCHI, Luiz Antônio. Produção textual, análise de gêneros e compreensão. São Paulo: Parábola, 2008.

TOKARNIA, Mariana. Quase 18\% dos alunos dizem sofrer bullying no Brasil, aponta estudo. 2017. https://educacao.uol.com.br/noticias/2017/04/19/quase18-dos-alunos-dizem-sofrer-bullying-no-brasil-diz-estudo.htm. Acesso em: 30 jan. 2017.

TRIPP, David. Pesquisa-ação: uma introdução metodológica. Revista Educação e Pesquisa, São Paulo, v. 31, n. 3, p. 443-466, set./dez. 2005. Disponível em: http://w0ww.scielo.br/pdf/ep/v31n3/a09v31n3.pdf. Acesso em: 30 jan. 2017. 